\title{
A TEORIA E A PRÁtICA dOS INTELECTUAIS NO PASSADO E NO PRESENTE
}

\author{
Diogo da Silva Roiz \\ Doutorando em História/UFPR \\ Professor Universidade Estadual de Mato Grosso do Sul/UEMS-Amambai \\ roizd@yahoo.com.br
}

SAID, EDWARD W. Representações do intelectual. As conferências Reith de 1993. Ttradução de Milton Hatoum. São Paulo: Companhia das Letras, 2005, 128p.

O que é ser intelectual? Qual sua função na sociedade? Como se organizam e como atuam? Quais as representações que foram construídas e elaboradas sobre o (trabalho do) intelectual? Foi com base neste tipo de questionamento que Edward W. Said no final de 1992 organizou suas palestras, que formariam as Conferências Reith, proferidas em 1993 nos Estados Unidos, a convite de Anne Winder. Edward W. Said nasceu em 1935 em Jerusalém e faleceu em 2003, aos 68 anos de idade. Durante sua trajetória de vida foi um intelectual engajado, que aproveitou seu campo de estudos, em literatura comparada, para evidenciar as trocas culturais entre o Ocidente e o Oriente, e denunciar as representações que o Ocidente construiu ao longo do tempo sobre o Oriente (até como forma de elaborar sua própria identidade) e a maneira como os países desenvolvidos do ocidente exploravam (e exploram) os países subdesenvolvidos (em processo de desenvolvimento). Sua produção é extensa. No Brasil já foram traduzidos seus livros: Orientalismo (1990); Cultura e imperialismo (1995); Reflexões sobre o exílio (2003); Paralelos e paradoxos (2003, com Daniel Barenboim) e Fora do lugar (2004), livro de memórias, no qual descreveu sua formação, trajetória acadêmica, suas discussões e exílio.

O seu livro Representações do intelectual foi originalmente apresentado, em 1993, como suas Conferências Reith, e lançado em 1994 com pequenos acréscimos. Apenas em 2005 foi traduzido no Brasil. Tal como foram apresentadas as conferências, em seis semanas, foi como permaneceu a divisão do livro, em seis capítulos. Já na introdução Said indica qual foi seu objetivo:

Com efeito, minha tentativa nessas conferências foi, antes de mais nada, falar de intelectuais precisamente como aquelas figuras cujo desempenho público não pode ser previsto nem forçado a enquadrar-se num slogan, numa linha partidária ortodoxa ou num dogma rígido. $\mathrm{O}$ que tentei sugerir é que os padrões de verdade sobre a miséria humana e a opressão deveriam ser mantidos, apesar da filiação partidária do 
intelectual enquanto indivíduo, das origens e de lealdades ancestrais. Nada distorce mais o desempenho público do intelectual do que os floreios retóricos, o silêncio cauteloso, a jactância patriótica e a apostasia retrospectiva e autodramática. (...) Para mim, o intelectual dirige-se a um público tão amplo quanto possível, que é sua platéia natural, em vez de desancálo. (...) Pessoas bem relacionadas promovem interesses particulares, mas são os intelectuais que deveriam questionar o nacionalismo patriótico, o pensamento corporativo e um sentido de privilégio de classe, raça ou sexo (SAID, 2005, p. 12-3).

O capítulo de abertura do livro, Representações do intelectual, já começa por discutir o que se entendeu por intelectual, e que tipo de representações foram elaboradas sobre seu trabalho e sobre seu papel na sociedade. Resume as idéias de Antônio Gramsci contidas nos seus Cadernos do cárcere, no qual discute o papel e a função do intelectual 'orgânico' e do intelectual 'tradicional', e de Julien Benda no seu livro $A$ traição dos intelectuais, que discute que "os verdadeiros intelectuais devem correr o risco de ser queimados na fogueira (...) [pois] São personagens simbólicos, marcados por sua distância obstinada em relação a problemas práticos. Por isso, não devem ser numerosos, nem desenvolver-se de modo rotineiro. Têm de ser indivíduos completos, dotados de personalidade poderosa e, sobretudo, têm de estar num estado de quase permanente oposição ao status quo" (Idem, p. 22), e segundo o autor "no fundo a retórica combativa da obra basicamente conservadora de Benda encontra-se essa figura do intelectual como um ser colocado à parte, alguém capaz de falar a verdade ao poder, um indivíduo ríspido, eloqüente, fantasticamente corajoso e revoltado, para quem nenhum poder do mundo é demasiado grande e imponente para ser criticado e questionado de forma incisiva" (Idem, p. 23). O que demonstra que enquanto para Gramsci o intelectual nasce do próprio interior dos problemas da sociedade, independentemente de sua origem social, para Benda este surge totalmente aquém a eles. Após inventariar a característica das obras de Gramsci e Benda, o autor se pergunta o que é ser intelectual hoje, argumentando que este "age com base em princípios universais", "são indivíduos com vocação para a arte de representar, seja escrevendo, falando, ensinando ou aparecendo na televisão. E essa vocação é importante na medida em que é reconhecível publicamente e envolve, ao mesmo tempo, compromisso e risco, ousadia e vulnerabilidade" (Idem, p. 27). De modo que na diversidade de definições sobre o que é o intelectual, pouca atenção foi dispensada as suas características pessoais, a sua imagem, desempenho e intenções "que, juntos, constituem a própria força vital de todo verdadeiro intelectual".

Não foi assim por acaso, que no capítulo seguinte, Manter nações e tradições à distância, o autor se esforce, desde o início para definir o que entende pelo 
trabalho do intelectual na sociedade (ainda que as variantes nacionais, étnicas e religiosas sejam importantes), pois, os intelectuais são "indivíduos cuja capacidade de pensamento e discernimento os torna capacitados para representar o melhor pensamento -, a própria cultura - fazendo-o prevalecer" (Idem, p. 41). Assim, foi se apoiando na argumentação de Matthew Arnold, que Edward Said definia o seu entendimento sobre o trabalho e a ação do intelectual na sociedade, coisa que estava construindo nas páginas anteriores. E inventariando o mapa de autores que pensaram o papel dos intelectuais, o autor prossegue dizendo que:

... o intelectual é sempre envolvido e implacavelmente desafiado pela questão da lealdade. Todos nós, sem exceção, pertencemos a algum tipo de comunidade nacional, religiosa ou étnica; ninguém, por maior que seja o volume de protestos, está acima dos laços orgânicos que vinculam o indivíduo à família, à comunidade e, naturalmente, à nacionalidade (Idem, $50)$.

O intelectual, nesse sentido, muitas vezes acaba sendo um indivíduo exilado, ou que procura se exilar, e esse foi o objetivo do capítulo três, Exílio intelectual, discutir o que foi o exílio para o intelectual. Com base na trajetória de vários outros intelectuais, a exemplo de: Ovídio, V. S. Naipaul, Henry Kissinger, Zbigniew Brzezinski, Thomas Mann, Leo Spitzer, Erich Auerbach, Jonathan Swift, Theodor W. Adorno, C. L. R. James, e o próprio autor poderia ser incluído a esta lista de intelectuais exilados, ou que procuraram se exilar, pois, segundo ele:

Para a maioria dos exilados, a dificuldade não consiste só em ser forçado a viver longe de casa, mas sobretudo, e levando em conta o mundo de hoje, em ter de conviver o tempo todo com a lembrança de que ele realmente se encontra no exílio, de que sua casa não está de fato tão distante assim, e de que a circulação habitual do cotidiano da vida contemporânea $o$ mantém num contato permanente, embora torturante e vazio, com o lugar de origem. Portanto, o exilado vive num estado intermediário, nem de todo integrado ao novo lugar, nem totalmente liberto do antigo, cercado de envolvimentos e distanciamentos pela metade; por um lado, ele é nostálgico e sentimental, por outro, um imitador competente ou um pária clandestino. A habilidade em sobreviver torna-se o principal imperativo, com o perigo de o exilado ficar acomodado e seguro em demasia, o que constitui uma ameaça contra a qual deve sempre prevenir (Idem, p. 56-7).

A postura, quase sempre, indomável do intelectual, nesse sentido, levou o autor a se questionar no capítulo seguinte, Profissionais e amadores, qual deve ser a ligação do intelectual com a sua ação. E argumenta que "espera-se que o intelectual 
seja ouvido e que, na prática, deva suscitar debate e, se possível, controvérsia". Tendo em vista que enquanto:

As representações do intelectual no século XIX tendiam a acentuar a individualidade; muitas vezes o intelectual é, como Bazárov de Turguêniev ou o Stephen Dedalus de Joyce, uma figura solitária, de certo modo arredia, que não se adapta de jeito nenhum à sociedade e é, por isso, um rebelde completamente à margem da opinião estabelecida. Com o crescente número de homens e mulheres do século XX que pertencem a um grupo geral chamado de intelectuais ou intelectualidade - gestores, professores, jornalistas, especialistas em computação ou em assuntos de governo, lobistas, eruditos, colunistas de agência de notícias, consultores pagos para dar suas opiniões -, somos levados a nos perguntar se o indivíduo intelectual, com uma voz independente, pode realmente existir (Idem, p. 74).

E constata que "o intelectual não representa um ícone do tipo estátua, mas uma vocação individual, uma energia, uma força obstinada, abordando com uma voz empenhada e reconhecível na linguagem e na sociedade uma porção de questões, todas elas relacionadas, no fim das contas, com uma combinação de esclarecimento e emancipação ou liberdade" (Idem, p. 78). E, por isso mesmo, está fadado a enfrentar um conjunto de pressões, tais como: a) "A especialização é a primeira dessas pressões"; b) "Se a especialização é um tipo de pressão geral e instrumental presente em todos os sistemas educacionais do mundo, a expertise e o culto do técnico ou perito credenciado são pressões mais próprias no mundo do pós-guerra"; c) “A terceira pressão do profissionalismo é a tendência inevitável para o poder e a autoridade entre seus adeptos, para as exigências e prerrogativas do poder e para se tornar diretamente empregado por ele". Concluindo que:

... o problema para o intelectual é tentar lidar com as restrições do profissionalismo moderno (...) sem fingir que elas não existem ou negando sua influência, mas representando um conjunto diferente de valores e prerrogativas. Chamarei essa atitude de amadorismo, literalmente uma atividade que é alimentada pela dedicação e pela afeição, e não pelo lucro e por uma especialização egoísta e estreita. O intelectual hoje deve ser um amador, alguém que, ao considerar-se um membro pensante e preocupado de uma sociedade, se empenha em levantar questões morais no âmago de qualquer atividade, por mais técnica e profissionalizada que seja (Idem, p. 86).

O intelectual, desse modo, deve ter um compromisso com a verdade. E é esse justamente o tema do capítulo seguinte, Falar a verdade ao poder, no qual o autor procurou desenvolver a concepção do intelectual, abordada no capítulo 
anterior, da seguinte forma: 1 - "o amadorismo significa uma opção pelos riscos e pelos resultados incertos da esfera pública - uma conferência, ou um livro, ou um artigo em circulação ampla e irrestrita - em vez do espaço para iniciados, controlado por especialistas e profissionais"; 2 - "emitir conhecimento em troca de remuneração é muito diferente de receber um convite de uma universidade para dar uma conferência pública ou para falar apenas para uma pequena platéia de funcionários"; 3 - "para ser mais político, todas as vezes em que fui solicitado para ajudar um grupo palestino ou convidado por uma universidade da África do Sul para falar contra o apartheid e a favor da liberdade acadêmica, sempre aceitei” (Idem, p. 91). Assim, o principal dilema enfrentado pelo intelectual no século XX é o de questionar e enfrentar o poder da autoridade (instituída). O grande problema, entretanto, é enfrentar as fronteiras hoje tênues do que seja a universalidade e se ela é possível de ser alcançada. Por outro lado, "o problema fundamental é como conciliar nossa própria identidade e as realidades de nossa própria cultura, sociedade e história com outras identidades, culturas e povos" (Idem, p. 96-7).

O objetivo de falar a verdade, sobretudo numa sociedade massificada e tão burocratizada como a nossa, é fazer uma análise mais profunda do estado de coisas, relacionando-a com mais rigor a um conjunto de princípios morais (...) e aplicada aos fatos conhecidos. (...) Falar a verdade ao poder (...) é pesar cuidadosamente as alternativas, escolher a certa e então representá-la de maneira inteligente, onde possa fazer o maior bem e causar a mudança correta (Idem, p. 101-2 e 104).

O intelectual, no exercício de sua conduta e de suas ações, também pode errar. É sobre isso que trata o último capítulo deste denso livro, Deuses que sempre falham, alertando que:

O verdadeiro intelectual é, por contraste, um ser secular. Apesar de muitos intelectuais desejarem que suas representações expressem coisas superiores ou valores absolutos, a conduta ética e os princípios morais começam com sua atividade no nosso mundo secular - onde tais princípios e conduta se realizam (...) Aqueles deuses que sempre falham acabam exigindo do intelectual uma espécie de certeza absoluta e uma visão total e sem costura da realidade, visão e certeza que reconhecem apenas discípulos ou inimigos. (...) $\mathrm{O}$ aspecto mais complicado de ser um intelectual é representar o que se professa por meio do trabalho e de intervenções, sem se enrijecer numa instituição ou tornar-se uma espécie de autômato agindo a mando de um sistema ou método. (...) Para o intelectual secular, esses deuses sempre falham (Idem, p. 120-1). 
Assim, a leitura deste livro nos permite não apenas refletir sobre o mundo em que vivemos hoje, mas também, e principalmente, pensar a atitude, os valores, a conduta e a ação com a qual teremos sobre ele. 